II.

\title{
A Case of Retention in Utero of the Separated After-coming Head.
}

\author{
By R. G. McKerron, M.A., M.D., \\ Physician to the Maternity Hospital, Aberdeen.
}

Mrs. O., a multipara, was admitted to the Aberdeen Maternity Hospital on the 5th of February, 1907, with the following history:-

About 3 o'clock in the morning, premature labour began, the patient being early in the seventh month of her sixth pregnancy and the membranes having ruptured four days before. In about half an hour, after a few strong pains, the breech and trunk were spontaneously expelled. There was no one in attendance on the woman, and, when the head did not follow, she endeavoured herself to complete delivery by pulling on the child, with the result that the trunk was torn off, leaving the head in utero.

On admission to the Hospital about 1-30 in the afternoon it was found that the uterine fundus reached to the level of the umbilicus and was markedly deflected to the right. The organ was soft and relaxed, showing no disposition to contract; there had been no pains from the time that the trunk was expelled. The woman complained of no discomfort or symptom of any kind, and the condition might easily have been overlooked had the body of the child not been seen by the practitioner who was sent for several hours after.

Vaginal examination showed the os uteri to have contracted to a size nearly equal to that of a half-crown, the torn umbilical cord protruding through it. The head could be felt in the uterine cavity with part of the vertebral column attached and lying over the os. The cervical ring was hard and unyielding. Under an anæsthetic, the os was dilated manually but with considerable difficulty. An endeavour was then made to extract the head by grasping the vertebral portion while an assistant pressed strongly down from above. Although a fairly good hold was obtained, it was found impossible to deliver through the rigid cervix. A volsella was next tried, but was not persevered with as the tissues at once gave way.

It being now clear that extraction could not be accomplished either with the hand or the volsella, I decided to try the midwifery forceps. Owing to the mobility of the head, considerable difficulty was experienced in securing a satisfactory hold. The under blade was applied easily enough, but the upper blade could not be adjusted. The former was removed and the upper blade inserted first, then, with 
some difficulty the lower blade was introduced. Notwithstanding the small size of the head, a good hold was obtained and extraction effected. The effort required, however, was so great as to make it clear that with the volsella, even if it had held, sufficient force could. not have been employed. After the removal of the placenta, which had to be effected manually, an intra-utcrine douche was given. The woman made a good recovery, though on the second day she had a rigor with a rise of temperature to $104 \cdot 8^{\circ}$. By next morning the temperature had fallen to $99^{\circ}$, and it did not rise above that level during the subsequent convalescence.

Separation of the after-coming head, with retention in utero, is probably a not uncommon accident. While it usually occurs in the case of long-dead decomposing children, in whom the tissncs are very friable, in the instance recorded the child was said to have been alive at the beginning of labour: at any rate the body was quite fresh, so that considerable force must have been used by the woman before the neck gave way.

When the after-coming head is retained in utoro its delivery is often a matter of considerable difficulty, more especially when its extraction has not been undertaken at once and the os uteri has had time to retract. In view of the comparative frequency of this accident and of the difficulties that may attend extraction, it is surprising to find that none of the standard text-books of midwifery deal with its treatment, indeed few of the writers even refer to it.

There are several ways in which extraction of the retained head may be effected. Sometimes expulsion is completed spontancously. This occurred in a case seen in consultation by a colleague of the writer's. The trunk of a premature child had been torn off in attempting to complete delivery. Before the necessary instruments could be obtained, the head was expelled by a few vigorous uterine contractions. Spontaneous delivery is probably exceptional; at any rate it should not bo waited for.

In a case reported by Valenta* the head of a full-term child, along with the placenta, was retained in the uterine cavity for forty days. Not only was thero no spontaneous attempt at expulsion, but all efforts to stimulate the uterus artificially were without effect. Freund records an even more remarkable case in which the head was retained in utero for ten years (Deutsche Klinit, 1869, Nr. 33†).

The sclection of a method of extraction will depend on the extent of the dilatation and on the dilatability of the cervix uteri. When the case is seen at once, before the cervix has retracted, firm downward

\footnotetext{
*Valenta. "Vierzint,̈̈gige Retention des Kopfes eines reifen Kindes sammt Placentarresten innerhalb der Gebärmutterhöhlen olne jedwede Reaction." Archiv. fïr Gyükol. Bd. xix. S, 431 .

† "Ueber Toleranz des weiblichen Genitalkanales gegen traumatische und septische Einwirkungen."
} 
pressure on the fundus may be sufficient, either alone or combined with moderate traction on the head by the hand or volsella. It is seldom that separation takes place at the immediate base of the skull; a part of the cervical column is usually left and affords a good hold for the hand. In another case seen by the writer, in which all the cervical vertebra were torn off, and where traction had pulled off the lower jaw, extraction was ultimately completed by getting the tip of the index finger through the foramen magnum, after several unsuccessful attempts had been made with the volsella.

When the cervix is imperfectly dilated, or is rigid and unyielding, great difficulty may be experienced in effecting extraction. The cervix must first be dilated, then, if a good grasp of the head cannot bo obtained with the hand, the volsella may be tried, but, if much force is required, it is not likely to be successful owing to the extreme friability of the tissues. Attempts to extract with the hand or the volsella should be combined with strong pressure from above. Should they fail the forceps may be tried. Owing to the mobility of the head the application may be troublesome, but this difficulty can usually be overcome by steadying the head from above. If a good hold is secured the head will usually be delivered readily. Where the head is small the forceps is apt to roll off or slip, as in the case referred to by Dr. Keiller in the Edinburgh Medical Journal of 1861,* in which he notes that "Forceps had rolled off several times, and hooks always slipped, and the hoad was only finally extracted in a very mutilated condition by means of two opposed crotchets used like forceps." On the other hand, when the head is large, or the pelvis contracted, perforation may be necessary after the forceps has been applied. In all cases of disproportion it is better to perforate than to risk laceration of the cervix by the employment of cxcessive force. In the event of failure with the forceps, the cephalotribe or cranioclast, both of which have been snccessfully used in these cases, may be tried. In Valenta's case the head was extracted piecemeal by means of a bent polypus-forceps.

In a recent paper on the treatment of this complication, Borgnis (Deutsche med. Wochenschr., 1906, Nr. 42, p. 1,707†) recommends as the best way of removal, when the cervix has become retracted, that the head should be fixed by means of a volsella or tumour forceps to which a weighted cord is attached and allowed to hang over the end of the bed. The continuous traction induces contractions of the uterus: dilatation is thus secured, after which the head can be delivered by traction on the volsella. Apart from the difficulty of obtaining a sufficient hold with the volsella, the chief objection to

* Mentioned in the course of remarks during a discussion on a paper by Dr. Pattison, read before the Edinburgh Obstetrical Society, February 27th, 1861.

tSee abstract in this Jovhis , 1907, vol. xi., p. 276. 
this plan is the danger of infection which the prolonged manipulation involves. Borgnis thinks that this can be sufficiently guarded against, and he quotes a case in which the method he describes was successfully employed, the head being in this way utilized as a dilator for 24 hours without any observable sign of infection.

It will be seen that the extraction of the after-coming head, retained in utoro, is sometimes an operation of great difficulty, requiring the exercise of manipulative skill and ingenuity, and certainly deserving of more consideration than has hitherto been given to it. 